\title{
Relative fracture risk in patients with diabetes mellitus, and the impact of insulin and oral antidiabetic medication on relative fracture risk
}

Received: 12 October 2004 / Accepted: 9 March 2005 / Published online: 21 May 2005

(C) Springer-Verlag 2005

\begin{abstract}
Aims/hypothesis: We studied the association between fractures and type 1 and type 2 diabetes mellitus. Methods: In this case-control study, all subjects diagnosed with a fracture $(n=124,655)$ in Denmark served as cases, and for each case three control subjects $(n=373,962)$ matched for sex and age were retrieved from the general population. Results: Type 1 and type 2 diabetes were associated with an increased risk (1) of any fracture (odds ratio $[\mathrm{OR}]=1.3,95 \% \mathrm{CI}: 1.2-1.5$ for type 1 diabetes and $1.2,95 \%$ CI: $1.1-1.3$ for type 2 diabetes after adjustment for confounders) and (2) of hip fractures $(\mathrm{OR}=1.7,95 \%$ CI: $1.3-2.2$ for type 1 diabetes, and $1.4,95 \%$ CI: $1.2-1.6$ for type 2 diabetes). Furthermore, type 2 diabetes was associated with a significant increase in forearm fractures $(\mathrm{OR}=1.2,95 \% \mathrm{CI}: 1.0-1.5)$, and type 1 diabetes was associated with an increased risk of spine fractures $(\mathrm{OR}=2.5$, 95\% CI: 1.3-4.6), whereas type 2 diabetes was not. Use of metformin and sulphonylureas was associated with a significantly decreased risk of any fracture, whereas a nonsignificant trend towards decreased risk of any fracture was associated with the use of insulin. Except for a decrease in hip fractures with use of sulphonylureas, no change in fracture risk in the hip, spine or forearm was associated with the use of insulin or oral antidiabetic drugs. Conclusions/interpretation: Type 1 and type 2 diabetes are associated with an increased risk of any fracture and hip fractures. The use of drugs to control diabetes may reduce the association between diabetes and fractures.
\end{abstract}

P. Vestergaard · L. Rejnmark · L. Mosekilde Department of Endocrinology and Metabolism C, Aarhus University Hospital,

Aarhus, Denmark

P. Vestergaard $(\bowtie)$

The Osteoporosis Clinic, Aarhus Amtssygehus,

Tage Hansens Gade 2,

8000 Aarhus C, Denmark

e-mail: p-vest@post4.tele.dk

Tel.: +45-89-497681

Fax: +45-89-497684
Keywords Diabetes · Epidemiology · Fracture - Insulin · Metformin $\cdot$ Risk $\cdot$ Sulphonylurea

Abbreviations ATC: Anatomical Therapeutical Chemical - BMD: bone mineral density - DDD: defined daily dose - GP: general practitioner - ICD: International Classification of Diseases - OR: odds ratio

\section{Introduction}

Calcium metabolism may be disturbed in patients with diabetes mellitus [1], depending on the type of diabetes [2]. The pathogenetic factors involve increased urinary calcium excretion [3, 4], and decreased intestinal calcium absorption [2]. This leads to a negative calcium balance with secondary hyperparathyroidism, increased bone turnover, and consequently a reduced bone mineral density (BMD). Furthermore, disturbances in vitamin D and parathyroid hormone metabolism are seen $[1,5]$, in particular in patients with renal disease [6]. Microvascular disease may compromise blood supply to the bones [7] leading to a decreased BMD. Diabetes influences endothelial function, and this may also contribute to a decreased BMD [8]. Finally, neuropathy may be accompanied by a decreased BMD [9]. Besides the alterations in calcium metabolism and $\mathrm{BMD}$, an increased risk of falls due to impaired eyesight in diabetic eye disease [10] or because of episodes of hypoglycaemia [11] may contribute to fracture risk.

Studies of BMD in persons with diabetes have yielded conflicting results. In type 1 diabetes most studies have reported a moderately decreased BMD $[2,4,12-18]$, whereas a normal to increased BMD has been reported in patients with type 2 diabetes [19-26], not entirely explained by overweight [2]. Insulin resistance may play a role in the changes in BMD [27].

From the BMD data one might expect an increased fracture risk in patients with type 1 diabetes and a normal to decreased fracture risk in patients with type 2 diabetes when all other factors for fracture are adjusted for. Previous studies have shown an increased risk of hip and humerus 
fractures in patients with type 1 diabetes [28, 29], and no increase in forearm fractures. However, the study samples have been limited in size [28]. Among patients with type 2 diabetes, an increased risk of hip and humerus fractures has been reported $[19,28]$ after adjustment for BMI and BMD [19]. This increase may be related to other factors besides BMD, such as risk of falls. However, persons with type 2 diabetes may have an increased BMD, and one study reported a decreased risk of fractures in women with type 2 diabetes [23]. Two studies did not distinguish between type 1 and type 2 diabetes, one reporting a decreased fracture risk [30], and the other an increased fracture risk [31]. Ivers et al. [10] reported that insulin-treated diabetes but not tablet- or diet-treated diabetes was associated with an increased risk of fracture, although insulin treatment improves some of the disturbances in calcium metabolism $[3,32]$.

We conducted a nationwide population-based casecontrol study on the relative risk of fractures in patients with type 1 diabetes and type 2 diabetes, adjusted for potential confounders, in order to assess the relative fracture risk associated with type 1 diabetes and type 2 diabetes and the effect of different treatment modalities (insulin and oral antidiabetic medication).

\section{Subjects and methods}

Study design The study was designed as a case-control study [33]. All subjects sustaining a fracture during the year 2000 in Denmark were included as cases $(n=124,655)$, and for each case three control subjects of the same age (same birth year) and sex were randomly selected from the general population of Denmark $(n=373,962)$. The exposure was presence of diabetes or not and use of antidiabetic medication or not. The odds ratios (ORs) were calculated for risk of fracture in patients with diabetes vs patients without diabetes and similarly for use of antidiabetic medication vs no use of antidiabetic medication. As this study is a casecontrol study the term 'case' denotes the presence of the outcome fracture and 'control' the absence of the outcome 'fracture', and the exposure is the presence or absence of diabetes in accordance with international standards [33]. Information on exposure variables was collected by the same methods in cases and control subjects. A ratio of three control subjects to one case was chosen based on power calculations showing that little would be gained from further increasing the number of control subjects per case. Furthermore, the more control subjects the higher the likelihood that a perfectly age- and sex-matched control could not be identified. This study was approved by the National Board of Health and the Danish Data Protection Agency.

End-points The case definition was any fracture between 1 January 2000 and 31 December 2000. All fractures were included at all ages, i.e. fractures in both children and adults, and fractures from high-energy traumas as well as low-energy and spontaneous fractures. Hip, spine and forearm fractures were analysed separately.
Exposure variables The prime exposure variable was presence of a diagnosis of: (1) type 1 diabetes; (2) type 2 diabetes; or (3) other non-specified types of diabetes from 1 January 1977 to 31 December 2000 or the date of fracture. The diabetes was diagnosed prior to the date of fracture, to avoid ascertainment bias at the time of fracture. The criteria for diagnosing type 1 diabetes, type 2 diabetes, and other types of diabetes followed the World Health Organization standards. All diagnoses, both main diagnoses and additional diagnoses (i.e. a patient mainly coming for treatment with a fracture, and having an additional diagnosis of arterial hypertension) were entered into the analysis. The secondary exposure was use of drugs to treat diabetes: (1) insulin, oral antidiabetic drugs; (2) sulphonylureas; (3) metformin; and (4) other oral antidiabetic drugs from 1 January to the date of censoring (date of fracture among cases or a similar dummy date among control subjects). Insulin was used in type 1 diabetics and type 2 diabetics.

The exposure was total number of defined daily doses (DDDs) consumed from 1996 to the date of censoring.

Other covariates included: (1) diseases or conditions known to affect fracture risk (e.g. prior stroke, acute myocardial infarction, and alcoholism); (2) use of medications reported to be associated with fracture risk (cholesterollowering drugs and antihypertensive drugs by diabetics); (3) number of contacts with the health service (hospitals, general practitioners [GPs] or specialists) as a proxy-variable for diabetes severity; and (4) social variables such as retirement, which may lead to social deprivation, which is linked to fracture risk [34].

The drugs associated with fracture risk were: (1) antiepileptic drugs [35]; (2) diuretics (thiazides, loop, potassium-sparing, and other types of diuretics) [36]; (3) sedatives, anxiolytics and hypnotics [37]; (4) neuroleptics [37]; (5) antidepressants [38]; (6) antihypertensive drugs; (7) statin and non-statin cholesterol-lowering drugs; and (8) glucocorticoids. The exposure was ever use of the drug in question from 1996 to the date of fracture among the cases and the date of censoring among the control subjects.

The social variables were: (1) working or not; (2) income in the year of the fracture; and (3) living alone or together with another person.

Registers used The information on fracture occurrence and occurrence of other diseases, prior fractures, alcoholism etc. came from two registers: (1) The National Hospital Discharge Register [39]; and (2) The Psychiatric Central Register [40].

The National Hospital Discharge Register was founded in 1977 [39]. It covers all inpatient contacts from 1977 to 1994, and from 1995 also all outpatient visits to hospitals, outpatient clinics and emergency rooms. Upon discharge, the physician in charge of the patient codes the reason for the contact using the International Classification of Diseases (ICD) system (see Appendix). The coding includes one main diagnosis (the main reason for the contact), and up to 16 supplementary diagnoses (i.e. a patient with type 1 diabetes may be hospitalised with a pneumonia, then the 
pneumonia is the main diagnosis, and the type 1 diabetes is the supplementary diagnosis). Any surgical procedures performed during the contact are also coded. The register has nationwide coverage and an almost $100 \%$ capture of contacts [39]. In general the validity of registrations is high [41], especially for fractures, where a precision of $97 \%$ has been reported [42].

The Psychiatric Central Register was founded in 1968 and covers all in- and outpatient contacts for Danish mental hospitals [40]. It has a nationwide coverage and a high validity of diagnoses has been reported [43]. This register also uses the ICD system for coding contacts.

Information on drug use among both patients and control subjects was obtained from The Danish Medicines Agency. This agency keeps a nationwide register of all drugs sold at pharmacies throughout the country from 1996 and onwards (The National Pharmacological Database run by the Danish Medicines Agency, http://www.dkma.dk). The drugs bought are registered by the person for whom the drugs were prescribed, the Anatomical Therapeutical Chemical (ATC) code of the drug sold (see Appendix), dosage sold and date of sale for the period 1 January 1996 to 31 December 2000.

Information on contacts with GPs and practising specialists came from the National Health Service. These contacts are registered by the date of the contact, and the type of contact. However, the contact is not coded with an ICD code.

Information on income was obtained from the Tax Authorities, and information on working status and marital status from the National Bureau of Statistics (Statistics Denmark).

It is possible to link these sources of information through the Central Person Number, which is a unique registration code given to every inhabitant - to some degree similar to the American Social Security Number - that allows registration on an individual basis.

The study was performed as a register-based study in accordance with the Declaration of Helsinki. It was approved by the Danish Board of Health and the Danish Data Protection Agency.

Statistical analyses Mean and SD were used as descriptive statistics. Crude ORs were calculated and 95\% CIs. A conditional logistic regression analysis for matched casecontrol studies - the type which allows $m$ to $n$ matching where not all cases need to have exactly the same number of controls - was used to assess the association between any fracture and the exposure variable [44]. Analyses were also performed sex- and age-stratified (A: $<15,15-49, \geq 50$ years, B: above and below 75 years, and $C:<59,50-74$ years, $\geq 75$ years - data not shown).

From the observation that the risk estimates for a fracture between the different types of diabetes were similar (see Results), the analysis of fracture risk in patients with complications of diabetes was pooled across diabetes types.

Analyses were performed using STATA 8.1 (STATA, College Station, TX, USA) and SPSS 10.1.0 (SPSS., Chicago, IL, USA), both in the UNIX version.
Table 1 Characteristics of cases (all fractures in Denmark in the year $2000, n=124,655)$ and of control subjects $(n=373,962$, age- and sex-matched from the total population of Denmark in the year 2000, $n=5,330,020)$

\begin{tabular}{lccc}
\hline Variable & Cases & $\begin{array}{c}\text { Control } \\
\text { subjects }\end{array}$ \\
\hline Age (years), mean \pm SD & $43 \pm 27$ & $43 \pm 27$ & - \\
Sex (\%) & & & \\
Men & 48.2 & 48.2 & - \\
Women & 51.8 & 51.8 & - \\
Previous fracture (\%) & 33.1 & 15.0 & $<0.01$ \\
Prior acute myocardial infarction (\%) & 2.5 & 2.1 & $<0.01$ \\
Prior stroke (\%) & 3.5 & 2.2 & $<0.01$ \\
Ever use of other diuretics (\%) & 3.8 & 3.8 & 0.93 \\
Ever use of potassium-sparing & 2.2 & 1.4 & $<0.01$ \\
$\quad$ diuretics (\%) & & & \\
Ever use of loop diuretics (\%) & 11.4 & 8.1 & $<0.01$ \\
Ever use of thiazide diuretics (\%) & 12.6 & 11.6 & $<0.01$ \\
Ever use of antihypertensive drugs (\%) & 16.0 & 15.2 & $<0.01$ \\
Ever use of statins (\%) & 1.5 & 1.6 & 0.02 \\
Ever use of non-statins (\%) & 0.24 & 0.21 & 0.05 \\
Ever use of any glucocorticoid (\%) & 54.3 & 50.7 & $<0.01$ \\
\hline
\end{tabular}

\section{Results}

Table 1 shows baseline characteristics of the cases and control subjects. Cases, more often than control subjects, were retired or living alone, and had a lower income. Cases also more often had concurrent diseases, and had been using medications. Only for prior fracture, prior use of loop diuretics, and prior use of any corticosteroid were major differences in terms of percent observed. Among the cases 26,220 were aged less than 15 years, and among the control subjects the number was 78,651 .

Table 2 Prevalence of use of diabetic and antidiabetic drugs among cases (all fractures in Denmark in the year 2000, $n=124,655$ ), and control subjects $(n=373,962$, age- and sex-matched from the total population of Denmark in the year 2000, $n=5,330,020$ )

\begin{tabular}{|c|c|c|c|}
\hline Variable & Cases & $\begin{array}{l}\text { Control } \\
\text { subjects }\end{array}$ & $p$ \\
\hline Type 1 diabetes $(\%)$ & 1.4 & 0.7 & $<0.01$ \\
\hline Type 2 diabetes (\%) & 2.6 & 1.7 & $<0.01$ \\
\hline $\begin{array}{l}\text { Non-specified types of } \\
\text { diabetes }(\%)\end{array}$ & 0.5 & 0.3 & $<0.01$ \\
\hline $\begin{array}{l}\text { Any prior episode of } \\
\text { hypoglycaemia }(\%)\end{array}$ & 0.6 & 0.4 & $<0.01$ \\
\hline Insulin (\%) & 1.5 & 0.9 & $<0.01$ \\
\hline Metformin (\%) & 0.8 & 0.8 & 0.18 \\
\hline Sulphonylureas (\%) & 2.0 & 1.8 & $<0.01$ \\
\hline $\begin{array}{l}\text { Other oral antidiabetic } \\
\text { drugs }(\%)\end{array}$ & 0.2 & 0.2 & 0.08 \\
\hline $\begin{array}{l}\text { Cumulated DDD for insulin } \\
(\text { mean } \pm \text { SD) }\end{array}$ & $1,767 \pm 1,352$ & $1,762 \pm 1,359$ & 0.91 \\
\hline
\end{tabular}

$D D D$ Defined daily dosage 
Table 3 Relative risk of any fracture here interpreted as odds ratio (OR) with 95\% CI for several variables in the population of Denmark in the year 2000 estimated in a case-control study by conditional logistic regression $(124,655$ fractures and 373,962 age- and sexmatched control subjects)

$D D D$ Defined daily dosages ${ }^{a}$ Adjusted for the variables in the table plus prior fracture, corticosteroid use, use of antiepileptic drugs, use of diuretics (loop, thiazide, potassium-sparing, other types), use of anxiolytics and sedatives, use of neuroleptics, use of antidepressants, alcoholism, use of statins and non-statin cholesterol-lowering drugs, use of antihypertensives, myocardial infarction, stroke, number of bed days in 1999, number of contacts to GP or specialists in 1999, working or not, income, living with another person vs living alone

\begin{tabular}{|c|c|c|c|c|c|c|}
\hline \multirow[t]{2}{*}{ Variable } & \multicolumn{3}{|l|}{ Crude } & \multicolumn{3}{|c|}{ Multiply-adjusted $^{\mathrm{a}}$} \\
\hline & OR & $\begin{array}{l}\text { Lower } \\
95 \% \text { CI }\end{array}$ & $\begin{array}{l}\text { Upper } \\
95 \% \text { CI }\end{array}$ & OR & $\begin{array}{l}\text { Lower } \\
95 \% \text { CI }\end{array}$ & $\begin{array}{l}\text { Upper } \\
95 \% \text { CI }\end{array}$ \\
\hline Type 1 diabetes vs no diabetes & 1.93 & 1.82 & 2.05 & 1.30 & 1.16 & 1.46 \\
\hline Type 2 diabetes vs no diabetes & 1.55 & 1.48 & 1.61 & 1.19 & 1.11 & 1.27 \\
\hline Non-specified types of diabetes & 2.14 & 1.95 & 2.36 & 1.20 & 1.07 & 1.34 \\
\hline $\begin{array}{l}\text { Prior episode of hypoglycaemia } \\
\text { vs no episode }\end{array}$ & 1.69 & 1.55 & 1.84 & 1.13 & 1.00 & 1.26 \\
\hline \multicolumn{7}{|l|}{ Insulin } \\
\hline$<1,000 \mathrm{DDD}$ & 1.65 & 1.50 & 1.81 & 1.04 & 0.92 & 1.18 \\
\hline 1,000-1,999 DDD & 1.67 & 1.49 & 1.87 & 0.85 & 0.73 & 1.00 \\
\hline$\geq 2,000 \mathrm{DDD}$ & 1.75 & 1.60 & 1.92 & 0.88 & 0.76 & 1.02 \\
\hline \multicolumn{7}{|l|}{ Metformin } \\
\hline$<150 \mathrm{DDD}$ & 1.07 & 0.95 & 1.22 & 0.87 & 0.76 & 1.01 \\
\hline 150-499 DDD & 1.06 & 0.93 & 1.20 & 0.81 & 0.71 & 0.94 \\
\hline$\geq 500$ DDD & 1.02 & 0.91 & 1.15 & 0.81 & 0.70 & 0.93 \\
\hline \multicolumn{7}{|l|}{ Sulphonylureas } \\
\hline$<400$ DDD & 1.17 & 1.08 & 1.27 & 0.88 & 0.80 & 0.96 \\
\hline 400-1,299 DDD & 1.14 & 1.06 & 1.24 & 0.82 & 0.75 & 0.90 \\
\hline$\geq 1,300$ DDD & 1.13 & 1.05 & 1.23 & 0.85 & 0.76 & 0.95 \\
\hline \multicolumn{7}{|l|}{ Other types of oral antidiabetics } \\
\hline$<45$ DDD & 1.16 & 0.90 & 1.50 & 1.03 & 0.79 & 1.36 \\
\hline 45-199 DDD & 1.00 & 0.77 & 1.28 & 0.89 & 0.68 & 1.17 \\
\hline$\geq 200 \mathrm{DDD}$ & 1.26 & 0.99 & 1.60 & 1.17 & 0.90 & 1.52 \\
\hline
\end{tabular}

Table 2 shows the prevalence of diabetes by type and use of antidiabetic drugs. Type 1 and type 2 diabetes and use of insulin and sulphonylureas were more common in cases than in control subjects (all $p$ values $<0.01$ ). The mean ingested dose (DDD) of insulin from 1996 to 2000 was similar in patients and control subjects.

Table 3 shows the crude and adjusted ORs for any fracture in cases compared with control subjects. In the mul-
Table 4 Relative risk of fractures at typical osteoporotic fracture sites here interpreted as odds ratio (ORs) with 95\% CIs for several variables in the population of Denmark in the year 2000 estimated in a casecontrol study by conditional logistic regression

Adjusted for prior fracture, corticosteroid use, use of anti-epileptic drugs, use of diuretics (loop, thiazide, potassium-sparing, other types), use of anxiolytics and sedatives, use of neuroleptics, use of antidepressants, alcoholism, use of statins and non-statin cholesterol-lowering drugs, use of antihypertensives, myocardial infarction, stroke, number of bed days in 1999, number of contacts to GP or specialists in 1999, working or not, income, living with another person vs living alone $N$ Number of cases/control subjects, $D D D$ defined daily dosage

\begin{tabular}{|c|c|c|c|c|c|c|c|c|c|}
\hline \multirow[t]{2}{*}{ Variable } & \multicolumn{3}{|c|}{$\begin{array}{l}\text { Hip } \\
(N=10,530 / 31,535)\end{array}$} & \multicolumn{3}{|c|}{$\begin{array}{l}\text { Forearm } \\
(N=20,035 / 60,030)\end{array}$} & \multicolumn{3}{|c|}{$\begin{array}{l}\text { Spine } \\
(N=3,364 / 10,079)\end{array}$} \\
\hline & OR & $\begin{array}{l}\text { Lower } \\
95 \% \text { CI }\end{array}$ & $\begin{array}{l}\text { Upper } \\
95 \% \text { CI }\end{array}$ & OR & $\begin{array}{l}\text { Lower } \\
95 \% \mathrm{CI}\end{array}$ & $\begin{array}{l}\text { Upper } \\
95 \% \text { CI }\end{array}$ & OR & $\begin{array}{l}\text { Lower } \\
95 \% \mathrm{CI}\end{array}$ & $\begin{array}{l}\text { Upper } \\
95 \% \text { CI }\end{array}$ \\
\hline Type 1 diabetes & 1.70 & 1.31 & 2.21 & 1.04 & 0.76 & 1.44 & 2.48 & 1.33 & 4.62 \\
\hline Type 2 diabetes & 1.38 & 1.18 & 1.60 & 1.21 & 1.01 & 1.45 & 1.34 & 0.97 & 1.86 \\
\hline Non-specified types of diabetes & 1.52 & 1.18 & 1.96 & 1.23 & 0.88 & 1.70 & 1.23 & 0.64 & 2.37 \\
\hline \multicolumn{10}{|l|}{ Insulin } \\
\hline$<1,000 \mathrm{DDD}$ & 1.18 & 0.88 & 1.57 & 0.99 & 0.70 & 1.39 & 0.53 & 0.26 & 1.09 \\
\hline 1,000-1,999 DDD & 0.70 & 0.69 & 1.01 & 1.13 & 0.74 & 1.72 & 0.21 & 0.09 & 0.52 \\
\hline$\geq 2,000 \mathrm{DDD}$ & 0.80 & 0.54 & 1.20 & 0.94 & 0.62 & 1.41 & 0.49 & 0.22 & 1.11 \\
\hline \multicolumn{10}{|l|}{ Metformin } \\
\hline$<150$ DDD & 0.70 & 0.49 & 1.02 & 0.71 & 0.48 & 1.04 & 1.16 & 0.58 & 2.34 \\
\hline 150-499 DDD & 1.05 & 0.76 & 1.46 & 0.89 & 0.60 & 1.31 & 0.52 & 0.23 & 1.14 \\
\hline$\geq 500 \mathrm{DDD}$ & 0.76 & 0.55 & 1.04 & 0.72 & 0.49 & 1.06 & 0.92 & 0.45 & 1.87 \\
\hline \multicolumn{10}{|l|}{ Sulphonylureas } \\
\hline$<400$ DDD & 0.86 & 0.70 & 1.05 & 0.91 & 0.71 & 1.15 & 0.89 & 0.57 & 1.38 \\
\hline 400-1,299 DDD & 0.77 & 0.63 & 0.95 & 0.81 & 0.63 & 1.03 & 1.03 & 0.65 & 1.62 \\
\hline$\geq 1,300 \mathrm{DDD}$ & 0.74 & 0.58 & 0.93 & 0.82 & 0.60 & 1.11 & 0.88 & 0.51 & 1.53 \\
\hline \multicolumn{10}{|l|}{ Other types of oral antidiabetics } \\
\hline$<45$ DDD & 1.22 & 0.64 & 2.33 & 1.01 & 0.53 & 1.95 & 1.66 & 0.52 & 5.31 \\
\hline 45-199 DDD & 0.90 & 0.49 & 1.65 & 0.61 & 0.25 & 1.48 & 0.33 & 0.04 & 2.81 \\
\hline$\geq 200$ DDD & 1.27 & 0.69 & 2.33 & 1.43 & 0.77 & 2.65 & 0.92 & 0.28 & 3.05 \\
\hline
\end{tabular}


Fig. 1 Relative risk of fractures at typical osteoporotic fracture sites by inclusion of diabetes duration in the population of Denmark in the year 2000 , estimated in a case-control study by conditional logistic regression. The relative risk is interpreted as odds ratios (OR) with 95\% CIs. a Type 1 diabetes, b type 2 diabetes, c non-specified type of diabetes. All panels are adjusted for prior fracture, corticosteroid use, use of antiepileptic drugs, use of diuretics (loop, thiazide, potassium-sparing, other types), use of anxiolytics and sedatives, use of neuroleptics, use of antidepressants, alcoholism, use of statins and non-statin cholesterol-lowering drugs, use of antihypertensives, myocardial infarction, stroke, number of bed days in 1999, number of contacts to GP or specialists in 1999, working or not, income, living with another person vs living alone a

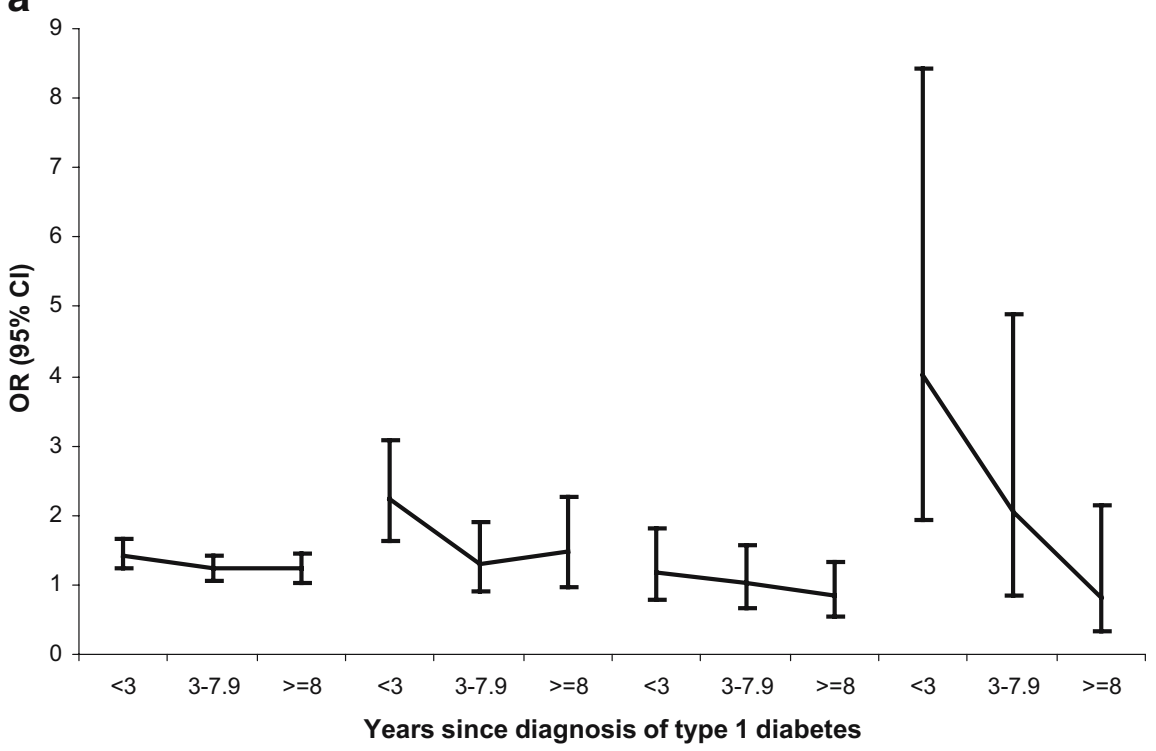

b

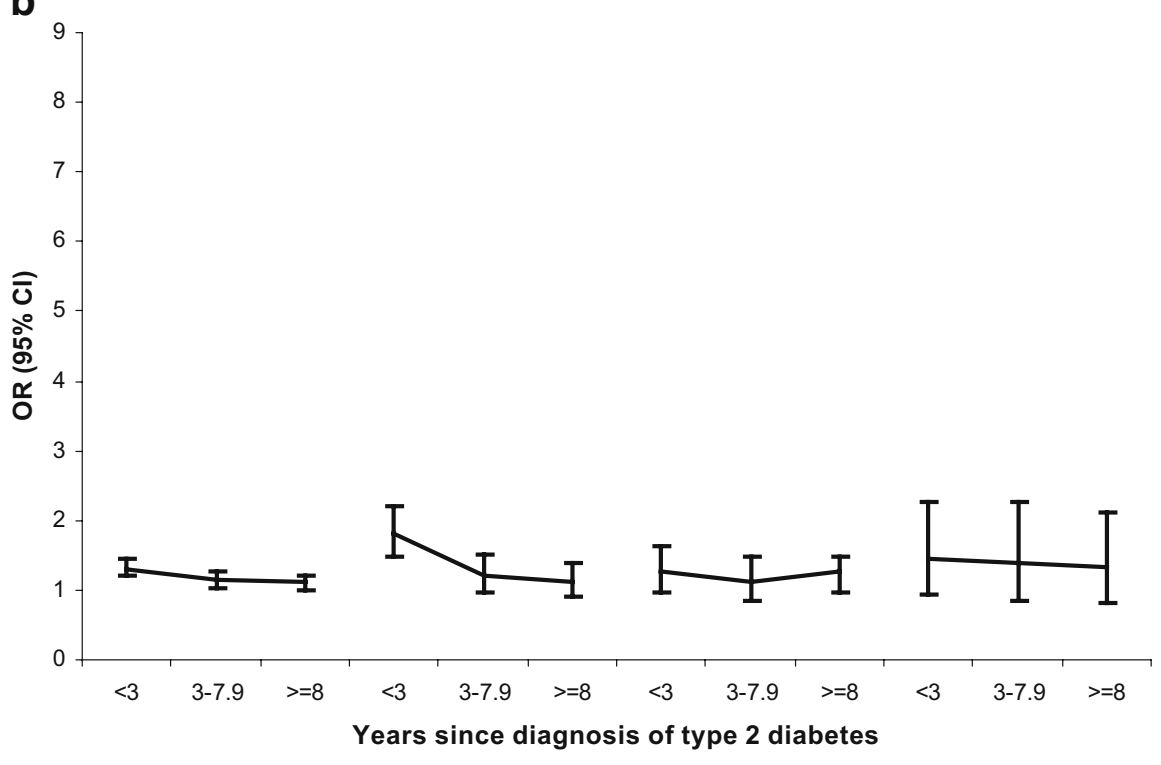

C

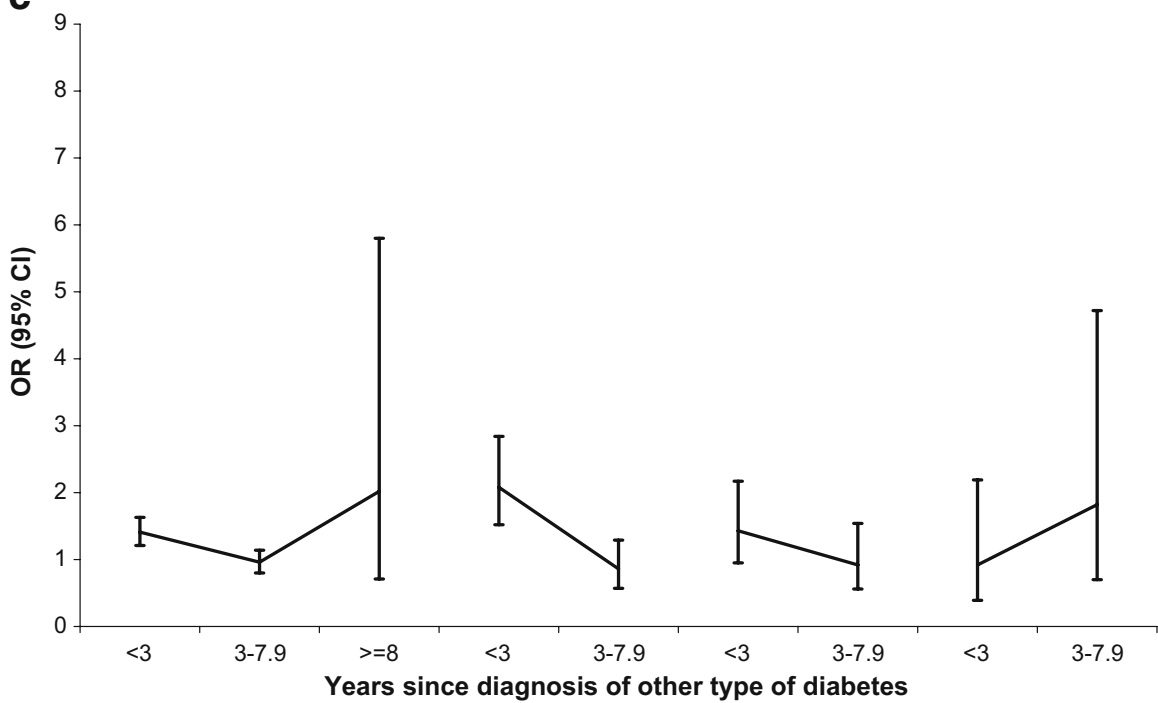


tiply-adjusted analysis, diabetes irrespective of type was associated with an increased fracture risk, while use of metformin and sulphonylureas were associated with a decreased risk of fractures. The increased fracture risk associated with insulin was reversed after adjustment for total number of defined daily doses used and confounders.

Prior episodes of hypoglycaemia were weakly associated with fracture risk after adjustment for the presence of diabetes. Even after adjustment for episodes of hypoglycaemia, diabetes was still associated with an increased fracture risk. Most episodes of hypoglycaemia were seen in type 1 diabetes, but some episodes in persons with type 2 diabetes were associated with the use of insulin and sulphonylureas.

Table 4 shows the adjusted risk of fractures in specific skeletal sites. All types of diabetes were associated with an increased fracture risk in the hip, while only type 1 diabetes was associated with a significantly increased spine fracture risk, and only type 2 diabetes was associated with an increase in forearm fracture risk. Use of all but the lowest daily doses of sulphonylureas was associated with a decreased fracture risk in the hip, while insulin was associated with a non-significant trend towards a reduction in fracture risk. No consistent association with antidiabetic drugs and fracture risk at the spine or forearm was observed.

Figure 1 shows no significant association of the duration of type 1 diabetes or type 2 diabetes.

\section{Discussion}

We have demonstrated an independent increased risk of any fracture risk and hip fracture associated with any type of diabetes (type 1, type 2 and other non-specified diabetes). Only type 2 diabetes was associated with an increased risk of forearm fractures, and type 1 diabetes with an increased risk of spine fractures. Antidiabetic drugsinsulin, sulphonylureas and metformin-were each associated with a decrease in fracture risk that was not apparent before adjusting for multiple covariates.

Strengths and weaknesses of the study The advantages of the study is that it is population-based and nationwide, i.e. not from selected populations at specialised clinics, who may have a much different risk profile. Selection and information bias are thought to be limited as probably nearly all subjects with a fracture are included and the validity of a fracture diagnosis is high.

One major drawback is that we have no information on BMI [45] or metabolic control $\left(\mathrm{HbA}_{1} \mathrm{c}\right)$ in the individual patient. In our study an increase in fracture risk is present in both type 1 and type 2 diabetes, and this was also reported in previous studies after adjustment for BMI $[19,28]$. Another disadvantage is that nearly all patients diagnosed with type 1 diabetes are captured because these patients are managed in hospital, but not all patients diagnosed with type 2 diabetes may be registered with a diagnosis of type 2 diabetes. This is because in Denmark the GP manages many of these patients, and they do not necessarily have their diagnosis registered in the hospital-based discharge registry. Any bias from patients with type 2 diabetes not being registered in the system would tend to underestimate the actual OR associated with type 2 diabetes, as the patients with type 2 diabetes who are not registered are classified with the control group presumed to be without type 2 diabetes. Further, many people in the general population have undiagnosed type 2 diabetes, which may also underestimate the odds of fracture associated with type 2 diabetes.

Strengths and weaknesses in relation to other studies In this study a case-control design was chosen because a cohort study would have required a very large sample of patients with diabetes followed for a long period of time to yield a sufficient number of fractures. The registry-based case-control design also provides the opportunity to study multiple risk factors at the same time. On the other hand, the case-control design does not allow calculation of fracture incidence.

Implications The use of antidiabetic drugs seemed to counter the detrimental effects of diabetes. This is most likely not the result of a direct antifracture effect of the antidiabetic drugs identical to the effects of anti-osteoporotic drugs, such as for example bisphosphonates. The fracture-reducing potential was only present with oral antidiabetic drugs at skeletal sites where diabetes was associated with an increase in fracture risk, i.e. in the hip. At the forearm, no substantial increase in fracture risk was present for type 1 diabetes, and no fracture-reducing potential was observed for insulin.

This raises an interesting possibility that the increase in fracture risk may be linked to hyperglycaemia. The mechanism whereby hyperglycaemia exerts negative effects on fracture risk is not entirely clear. In an experimental study, glucose administration showed negative effects on both bone formation and bone resorption [46]. In a rat model of type 1 diabetes, improved metabolic control reversed the negative consequences of poor metabolic control on bone healing [47]. Among adolescents with type 1 diabetes, poor metabolic control was associated with a negative effect on bone mineral acquisition [48].

In our study, diabetes duration was not associated with fracture risk - in fact the relative risk of fracture tended to be higher in those with less than 3 years of diabetes than in those with diabetes of longer duration. This could be the result of initial poor control of diabetes with control improved over time. This could especially be of significance in patients with type 2 diabetes, who may have been asymptomatic for a long period before diagnosis.

In patients with type 2 diabetes, an increase in BMD [2] is often observed. However, in contrast to the expected decrease in fracture risk, the present study reveals an actual increase in the risk of hip and forearm fractures. In type 1 diabetes, weight loss, metabolic acidosis and hypoglycaemia may contribute to fracture risk, while vision loss, neuropathy and obesity may be of greater significance in type 2 diabetes. 
In our study a trend towards an increase in fracture risk was present in patients with prior episodes of hypoglycaemia, and this trend was statistically significant for hip fractures. This is probably the result of a hypoglycaemiainduced risk of falls and thus fractures. Many episodes may be treated at home and thus not registered at the hospitals, with only the more severe episodes coming to hospital; many of these do not result in falls, as the subject is found unconscious. Thus the association between hypoglycaemia and fracture is probably underestimated in this study.

The overall number of fractures in the year 2000 $(n=124,655)$ was small compared with the population size ( $n=5,330,020$ - rate $2.3 \% /$ year); therefore the calculated ORs could be interpreted as approximate relative risks. Caution is required for the interpretation of the $p$ values in Table 1, because the large number of subjects means that small clinically insignificant differences may become statistically significant.

In conclusion, these data show that both type 1 and type 2 diabetes are associated with an increased risk of any fracture and hip fracture. Forearm fractures were associated with type 2 diabetes, and spine fractures with type 1 . The use of drugs to control diabetes may reduce the diabetesfracture associations. These results need confirmation from other studies.

Acknowledgements The National Bureau of Statistics (Statistics Denmark) is acknowledged for their help, without which this project would not have been possible. Financial support was provided by the Danish Medical Research Council (Grant number 22-04-0495).

\section{Appendix}

List of all codes for drugs (ATC codes) and diseases (ICD8 and 10) referred to in the study as outcome (any fracture) or exposure (type of diabetes, types of antidiabetic drugs used).

\begin{tabular}{|c|c|c|}
\hline Diabetes & ICD 8 codes & ICD 10 codes \\
\hline $\begin{array}{l}\text { Type } 1 \\
\text { diabetes }\end{array}$ & $24,900-24,909$ & E100-E109 \\
\hline $\begin{array}{l}\text { Type } 2 \\
\text { diabetes }\end{array}$ & $25,000-25,009$ & E110-E119 \\
\hline $\begin{array}{l}\text { Other non- } \\
\text { specified types } \\
\text { of diabetes }\end{array}$ & - & $\begin{array}{l}\text { E120-E129, } \\
\text { E130-E139, } \\
\text { E140-E149 }\end{array}$ \\
\hline Drug & ATC code & \\
\hline Insulin & $\begin{array}{l}\text { A10AB01, A10AB04, } \\
\text { A10AB05, A10AC01, } \\
\text { A10AD01, A10AD04, } \\
\text { A10AD05 }\end{array}$ & \\
\hline Sulphonylureas & $\begin{array}{l}\text { A10BB01 (glibenclamide), } \\
\text { A10BB03 (tolbutamide), } \\
\text { A10BB07 (glipizide), } \\
\text { A10BB09 (gliclazide), } \\
\text { A10BB12 (glimepiride) }\end{array}$ & \\
\hline
\end{tabular}

\begin{tabular}{ll}
\hline Drug & ATC code \\
\hline Metformin & A10BA02 \\
Other types & A10BF01 (acarbose), \\
of oral & A10BG02 (rosiglitazone), \\
antidiabetic & A10BG03 (pioglitazone), \\
drugs & A10BX02 (repaglinide), \\
& A10BX03 (nateglinide) \\
\hline
\end{tabular}

Any fracture: ICD10 codes: S02.0-S02.9, S07.0-S07.9, $\mathrm{S} 12.0-\mathrm{S} 12.9, \mathrm{~S} 22.0-\mathrm{S} 22.9, \mathrm{~S} 32.0-\mathrm{S} 32.8, \mathrm{~S} 42.0-\mathrm{S} 42.9$, S52.0-S52.9, S62.0-S62.9, S72.0-S72.9, S82.0-S82.9, S92.0-S92.9

\section{References}

1. Bouillon R (1991) Diabetic bone disease [editorial]. Calcif Tissue Int 49:155-160

2. Carnevale V, Romagnoli E, D'Erasmo E (2004) Skeletal involvement in patients with diabetes mellitus. Diabetes Metab Res Rev 20:196-204

3. Raskin P, Stevenson MRM, Barilla DE, Pak CYC (1978) The hypercalciuria of diabetes mellitus: its amelioration with insulin. Clin Endocrinol 9:329-335

4. McNair P, Madsbad S, Christensen MS et al (1979) Bone mineral loss in insulin-treated diabetes mellitus: studies on pathogenesis. Acta Endocrinol 90:463-472

5. Storm TL, Sørensen OH, Lund BJ et al (1983) Vitamin D metabolism in insulin-dependent diabetes mellitus. Metab Bone Dis Relat Res 5:107-110

6. Nisbeth U, Lindh E, Ljunghall S, Backman U, Fellstrom B (1999) Increased fracture rate in diabetes mellitus and females after renal transplantation. Transplantation 67:1218-1222

7. Vogt MT, Cauley JA, Kuller LH, Nevitt MC (1997) Bone mineral density and blood flow to the lower extremities: the study of osteoporotic fractures. J Bone Miner Res 12:283-289

8. Sanada M, Taguchi A, Higashi Y et al (2004) Forearm endothelial function and bone mineral loss in postmenopausal women. Atherosclerosis 176:387-392

9. Rix M, Andreassen H, Eskildsen P (1999) Impact of peripheral neuropathy on bone density in patients with type 1 diabetes. Diabetes Care 22:827-831

10. Ivers RQ, Mitchell P, Cumming RG, Peduto AJ (2001) Diabetes and risk of fractures-the Blue Mountains Eye Study. Diabetes Care 24:1198-1203

11. Nabarro JD (1985) Compression fractures of the dorsal spine in hypoglycaemic fits in diabetes. Br Med J (Clin Res Ed) 291: 1320

12. De Schepper J, Smitz J, Rosseneu S, Bollen P, Louis O (1998) Lumbar spine bone mineral density in diabetic children with recent onset. Horm Res 50:193-196

13. Hui SL, Epstein S, Johnston CC Jr (1985) A prospective study of bone mass in patients with type I diabetes. J Clin Endocrinol Metab 60:74-80

14. Munoz-Torres M, Jodar E, Escobar-Jimenez F, Lopez-Ibarra PJ, Luna JD (1996) Bone mineral density measured by dual X-ray absorptiometry in Spanish patients with insulin-dependent diabetes mellitus. Calcif Tissue Int 58:316-319

15. Ponder SW, McCormick DP, Fawcett HD et al (1992) Bone mineral density of the lumbar vertebrae in children and adolescents with insulin-dependent diabetes mellitus. J Pediatr 120: $541-545$

16. Shore RM, Chesney RW, Mazess RB, Rose PG, Bargman GJ (1981) Osteopenia in juvenile diabetes. Calcif Tissue Int 33: 455-457 
17. Tuominen JT, Impivaara O, Puukka P, Ronnemaa T (1999) Bone mineral density in patients with type 1 and type 2 diabetes. Diabetes Care 22:1196-1200

18. Wiske PS, Wentworth SM, Norton JA Jr, Epstein S, Johnston CC Jr (1982) Evaluation of bone mass and growth in young diabetics. Metabolism 31:848-854

19. Schwartz AV, Sellmeyer DE, Ensrud KE et al (2001) Older women with diabetes have an increased risk of fracture: a prospective study. J Clin Endocrinol Metab 86:32-38

20. Strotmeyer ES, Cauley JA, Schwartz AV et al (2004) Diabetes is associated independently of body composition with BMD and bone volume in older white and black men and women: the health, aging, and body composition study. J Bone Miner Res 19:1084-1091

21. Barret-Connor E, Holbrook TL (1992) Sex differences in osteoporosis in older adults with non-insulin-dependent diabetes mellitus. JAMA 268:3333-3337

22. Johnston CC Jr, Hui SL, Longcope C (1985) Bone mass and sex steroid concentration in postmenopausal Caucasian diabetics. Metabolism 34:544-550

23. van Daele PL, Stolk RP, Burger H et al (1995) Bone density in non-insulin-dependent diabetes mellitus. The Rotterdam Study [see comments]. Ann Intern Med 122:409-414

24. Wakasugi M, Wakao R, Tawata M, Gan N, Koizumi K, Onaya $\mathrm{T}$ (1993) Bone mineral density measured by dual energy X-ray absorptiometry in patients with non-insulin-dependent diabetes mellitus. Bone 14:29-33

25. Weinstock RS, Goland RS, Shane E, Clemens TL, Lindsay R, Bilezikian JP (1989) Bone mineral density in women with type II diabetes mellitus. J Bone Mineral Res 4:97-101

26. Bauer DC, Browner WS, Cauley JA et al (1993) Factors associated with appendicular bone mass in older women. The Study of Osteoporotic Fractures Research Group [see comments]. Ann Intern Med 118:657-665

27. Dennison EM, Syddall HE, Aihie SA, Craighead S, Phillips DI, Cooper C (2004) Type 2 diabetes mellitus is associated with increased axial bone density in men and women from the Hertfordshire Cohort Study: evidence for an indirect effect of insulin resistance? Diabetologia 47:1963-1968

28. Forsen L, Meyer HE, Midthjell K, Edna TH (1999) Diabetes mellitus and the incidence of hip fracture: results from the Nord-Trondelag Health Survey. Diabetologia 42:920-925

29. Kelsey JL, Browner WS, Seeley DG, Nevitt MC, Cummings SR (1992) Risk factors for fractures of the distal forearm and proximal humerus. Am J Epidemiol 135:477-489

30. Melton LJ III, Achenbach SJ, O'Fallon WM, Khosla S (2002) Secondary osteoporosis and the risk of distal forearm fractures in men and women. Bone 31:119-125

31. Vogt MT, Cauley JA, Tomaino MM, Stone K, Williams JR, Herndon JH (2002) Distal radius fractures in older women: a 10-year follow-up study of descriptive characteristics and risk factors. The study of osteoporotic fractures. J Am Geriatr Soc 50:97-103

32. Gertner JM, Tamborlane WV, Horst RL, Sherwin RS, Felig P, Genel M (1980) Mineral metabolism in diabetes mellitus: changes accompanying treatment with portable subcutaneous insulin infusion system. J Clin Endocrinol Metab 50:862-866
33. Rothman KJ (2002) Epidemiology — an introduction. Oxford University, Oxford

34. Jones S, Johansen A, Brennan J, Butler J, Lyons RA (2004) The effect of socioeconomic deprivation on fracture incidence in the United Kingdom. Osteoporosis Int 15:520-524

35. Vestergaard P, Tigaran S, Rejnmark L, Tigaran C, Dam M, Mosekilde L (1999) Fracture risk is increased in epilepsy. Acta Neurol Scand 99:269-275

36. Jones G, Nguyen T, Sambrook PN, Eisman JA (1995) Thiazide diuretics and fractures: can meta-analysis help? J Bone Miner Res 10:106-111

37. Ray WA, Griffin MR, Schaffner W, Baugh DK, Melton LJ III (1987) Psychotropic drug use and the risk of hip fracture. N Engl J Med 316:363-369

38. Ensrud KE, Blackwell T, Mangione CM et al (2003) Central nervous system active medications and risk for fractures in older women. Arch Intern Med 163:949-957

39. Andersen TF, Madsen M, Jørgensen J, Mellemkjær L, Olsen JH (1999) The Danish national hospital register. Dan Med Bull 46:263-268

40. Munk-Jørgensen P, Mortensen PB (1997) The Danish psychiatric central register. Dan Med Bull 44:82-84

41. Mosbech J, Jørgensen J, Madsen M, Rostgaard K, Thornberg K, Poulsen TD (1995) The Danish national patient register: evaluation of data quality. Ugeskr Læger 157:3741-3745

42. Vestergaard P, Mosekilde L (2002) Fracture risk in patients with celiac disease, Crohn's disease, and ulcerative colitis: a nationwide follow-up study in 16,416 patients in Denmark. Am J Epidemiol 156:1-10

43. Vestergaard P, Emborg C, Støving RK, Hagen C, Mosekilde L, Brixen K (2002) Fractures in patients with anorexia nervosa, bulimia nervosa, and other eating disorders-a nation-wide register study. Int J Eating Disord 32:301-308

44. STATA (2003) STATA statistical software: release 8.0. STATA Corp., College Station, TX

45. Hemenway D, Colditz GA, Willett WC, Stampfer MJ, Speizer FE (1988) Fractures and lifestyle: effect of cigarette smoking, alcohol intake, and relative weight on the risk of hip and forearm fractures in middle-aged women. Am J Public Health 78:1554-1558

46. Clowes JA, Allen HC, Prentis DM, Eastell R, Blumsohn A (2003) Octreotide abolishes the acute decrease in bone turnover in response to oral glucose. J Clin Endocrinol Metab 88:48674873

47. Follak N, Klöting I, Wolf E, Merk H (2004) Improving metabolic control reverses the histomorphometric and biomechanical abnormalities of an experimentally induced bone deficit in spontaneously diabetic rats. Calcif Tissue Int 74:551-560

48. Moyer-Mileur LJ, Dixon SB, Quick JL, Askew EW, Murray MA (2004) Bone mineral acquisition in adolescents with type 1 diabetes. J Pediatr 145:662-669 